\title{
REEXAMEN DE UN PROBLEMA DE LA DIALECTOLOGÍA DEL CARIBE HISPÁNICO. EL ORIGEN DE LA "VOCALIZACIÓN CIBAEÑA" EN SU CONTEXTO ANTILLANO
}

El proceso de semivocalización o, más exactamente, de desconsonantización de /R/ y /L/ en determinados contextos silábicos postnucleares es, posiblemente, el rasgo fonético más notable de la dialectología del español dominicano y ello no sólo por su considerable extensión diatópica que, en alguna zona concreta como Yamasá, llega hasta las inmediaciones de la ciudad capital o por su extraordinaria vitalidad sociolingüística ${ }^{1}$ sino, y sobre todo, por su fisonomía extremadamente radical ${ }^{2}$ desde el punto de vista fonológico que ha dado lugar a que $\mathrm{O}$. Alba ${ }^{3}$ haya podido caracterizarla, acertadamente, como "exótica" en relación con las demás realizaciones, paralelas, de /R/ y /L/ implosivas que se dan en el resto del área hispanófona caribeña.

Quizá por este motivo son relativamente numerosos los trabajos y monografías que se han dedicado a examinar el fenómeno en cuestión desde muy diferentes (y a veces contradictorios) enfoques teóricos, circunstancia que por cierto contrasta vivamente con la escasez o inexistencia de investigaciones que se ocupen, dentro de la dialectología del español de la República Dominicana, de otros rasgos o incluso niveles lingüísticos completos que requie-

1 Véase, sobre este punto, I. Pérez Guerra, "Un caso de prestigio encubierto en el español dominicano: la vocalización cibaeña", en Actas del III Congreso Internacional sobre el Español de América (en prensa).

${ }^{2}$ Empleo el término en el sentido que le ha sido atribuido por Jorge $\mathrm{M}$. Guitart (máximo distanciamiento entre la representación fonológica subyacente y la correspondiente realización fonética). Cf. Jorge M. GuitarT, "Conservative versus radical dialects in Spanish. Implications for language instruction", Bilingual Review, 5 (1978), 57-64 y Juan C. Zamora Munné y Jorge M. Guitar T, Dialectologia hispanoamericana. Teoria. Descripción. Historia, Almar, Salamanca, 1982 (esp. pp. 107-108).

3 "Análisis fonológico de las líquidas implosivas en un dialecto rural de la República Dominicana", BAPul, 7 (1979), 1-18. 
ren, del mismo modo, estudios adecuados y, a ser posible, de realización urgente ${ }^{4}$. Así, por ejemplo, han sido cuidadosamente delimitadas las zonas territoriales dominicanas en las que se da la desconsonantización de /R/ y /L/ postnucleares por Jiménez Sabater $^{5}$ y L. Coupal ${ }^{6}$; han descrito con apreciable exactitud las modalidades fonéticas que revisten los resultados del mencionado proceso los autores mencionados ${ }^{7}$ y N. Rojas ${ }^{8}$; han analizado, a la luz de diferentes modelos teóricos recientes, los mecanismos de generación del rasgo fonológico que nos ocupa $\mathrm{O}$. Alba ${ }^{9}$, J. M. Guitart ${ }^{10}$, N. Rojas ${ }^{11}$ y J. W. Harris ${ }^{12}$ y, finalmente, han determinado (llegando, por cierto, a conclusiones ampliamente divergentes entre sí) el perfil sociolingüístico que es atribuible en diferentes áreas del país a las realizaciones desconsonantizadas de las líquidas postnucleares autores como: O. Alba ${ }^{13}, \mathrm{~N}$. Rojas ${ }^{14}$,

${ }^{4}$ Véase una enumeración sucinta de los mismos en G. DE Granda e I. PÉrez Guerra, "Sobre los componentes canario y africano del léxico del español dominicano. A propósito de me(s)turado y toto', $A L M, 27$ (1989), 281 294 (esp. pp. 282-283).

${ }^{5}$ Cf. 'Más datos sobre el español de la República Dominicana, $2^{\mathrm{a}}$ ed., Instituto Tecnológico de Santo Domingo, Santo Domingo, 1984, pp. 88-105.

${ }^{6} \mathrm{~L}$. Coupal et al., "La /R/ y la /L/ en la costa norte dominicana. Nuevos aportes para la delimitación del dialecto cibaeño', ALHis, 4 (1988), 43-79.

7 Véanse A. Jiménez Sabater, op. cit., L. Coupal, art. cit. y Max A. JiMÉNEz SABATER, "La neutralización de /-R/ y /-L/ en el dialecto dominicano. Puesta al día sobre un tema en debate', ALHis, 2 (1986), 119-152.

8“ "Sobre la semivocalización de las líquidas en el español cibaeño”, en O. Alba (ed.), El español del Caribe, Santiago de los Caballeros, 1982, pp. 271-287.

${ }^{9}$ O. Alba, art. cit. Cf. también "Análisis fonológico de /R/ y /L/ implo" sivas en un dialecto rural dominicano", EME EME. Estudios Dominicanos, 74 (1984), 53-73.

10 "Some theoretical implications of liquid gliding in Cibaeño Dominican Spanish", Papers in Romance, 3 (1981), 223-228; "Variable rules in Caribbean Spanish and the organization of phonology", en F. Nuessel (ed.), Current issues in Hispanic phonology and morphology, Indiana University Linguistic Club, Bloomington, 1985, pp. 28-33 y "The case for a syntax-dependent postlexical module in Spanish phonology", en D. Birdsong y J. P. Montreuil (eds.), Advances in Romance linguistics, Dordrecht, 1988, pp. 89-96.

11 "Fonología de las líquidas en el español cibaeño", en R. M. HAMmond y M. C. Resnick (eds.), Studies in Caribbean Spanish dialectology, Georgetown University Press, Washington, 1988, pp. 103-111.

${ }^{12}$ Syllable structure and stress in Spanish: a nonlinear analysis, MIT Press, Cambridge, MA, 1983 (esp. cap. 3).

13 "La variation de /R/ dans l'espagnol de Santiago", en D. SAnKoff (ed.), Diversity and diachrony, Benjamins, Amsterdam-Philadelphia, 1986, pp. 211-222, y "Estudio sociolingüístico de la variación de las líquidas finales de 
M. A. Jiménez Sabater ${ }^{15}$, L. Coupal ${ }^{16}$ y C. González Tapia ${ }^{17}$. Frente a esta abundancia de monografías de índole teórica, fonética, sociolingüística o relacionable con la dialectología diatópica, los análisis, de índole histórica, que intentan determinar los factores genéticos del rasgo dominicano de que aquí nos ocupamos, se reducen, en este caso, a un valiosos pero aislado trabajo de P. Golibart ${ }^{18}$, lo que no deja de ser sorprendente sobre todo si tomamos en cuenta en su justo significado la reciente revalorización realizada por E. Coseriu ${ }^{19}$ del enfoque histórico en el estudio de la lingüística, y la aún más reciente aplicación que ha hecho de este punto de vista teórico respecto a la investigación del español de América G. L. Guitarte ${ }^{20}$.

Ahora bien (y prescindiendo por el momento de otras observaciones críticas que expondré más adelante), el interesante texto de Golibart que acabamos de mencionar adolece de un fallo metodológico primario que lo imposibilita, a priori, para dar razón adecuadamente del problema teórico que intenta abordar. Me refiero a la consideración, prácticamente exclusiva, que hace el investigador mencionado de datos solamente dominicanos para fundamentar, sobre ellos, sus tesis respecto a la denominada generalmente vocalización cibaeña, dejando así de lado no sólo la ineludible necesidad metodológica de incluir los fenómenos dominicanos en cuestión dentro del contexto antillano o, más ampliamente, hispanoamericano lo que, como recordaba acertadamente J. Lüdtke ${ }^{21}$

palabra en el español cibaeño", en R. M. Hammond y M. C. Resnick (eds.), Studies in Caribbean Spanish dialectology, Washington, 1988, pp. 11-12.

${ }^{14} \mathrm{~N}$. Rojas, art. cit.

${ }^{15}$ Max A. Jiménez Sabater, art. cit.

${ }^{16}$ L. Coupal, art. cit.

17 "El español dominicano. Un estudio diatópico de /R/ y /L/", ALHis, 6 (1990), 225-254.

18 "Orígenes de la vocalización en el habla cibaeña", EME EME. Estudios Dominicanos, 22 (1976), 127-143.

${ }^{19}$ Véanse especialmente "Humanwissenschaften und Geschichte. Der Gesichtspunkt eines Linguisten", Det Norske Videnskaps Akademi. Arbok, 1978, Oslo, 1979, pp. 118-130 y "Vom Primat der Geschichte", Sprachwissenchaft, Heidelberg, 5 (1980), 125-145.

20 "Dialecto, español de América e historia en Coseriu", Energeia und Ergon, Tübingen, 2 (1988), 487-500.

21 "'La historia de la lengua de un país [Puerto Rico] no es, en rigor, posible, como demuestra claramente la propia obra de Álvarez Nazario[... ] la historia lingüística de Puerto Rico comprende, por lo menos, el desarrollo del español antillano en su conjunto [...] la implantación del español en Haití y [...] los influjos indígena y africano en las Antillas", en J. LüdTKe, "Pro- 
en un artículo de aparición muy reciente, es totalmente indispensable para facilitar el adecuado marco de referencia al tema estudiado, sino también (lo que es aún más grave) eludiendo la correcta valoración, imprescindible para el planteamiento eficaz de la problemática examinada por P. Golibart, de los rasgos, homólogos, que están (o estuvieron) presentes en el español de Cuba y de Puerto Rico y que se conectan, igual que en Santo Domingo, con el proceso global antillano de desconsonantización de /R/ y /L/ postnucleares.

En efecto, los tres territorios caribeños de habla española comparten el fenómeno de la realización no consonántica de las líquidas implosivas silábicas aunque se dan en ellos, junto con determinadas semejanzas, algunas notables diferencias. Coinciden todos ellos, en primer lugar, en las modalidades generales del proceso y en los resultados del mismo. Y, además, en las fechas de los primeros testimonios de la existencia de este rasgo en cada una de las islas, 1820 para Puerto Rico ${ }^{22}, 1821$ para Santo Domingo $^{23}, 1836$ para $\mathrm{Cuba}^{24}$, lo que hace pensar en que el surgimiento del mismo debió ser simultáneo (o casi) en los tres territorios y situable plenamente dentro del siglo xvirr. Y coinciden, también, en la vigencia de este fenómeno, tanto en Cuba como en Puerto Rico y Santo Domingo, durante el siglo xix, como lo indican, respecto a Cuba, el testimonio de A. Bachiller y Morales en $1883^{25}$, para Puerto Rico los de Manuel Alonso en $1843^{26}$,

yecto de una historia del español ultramarino", Actas del I Congreso Internacional de Historia de la Lengua Española, Madrid, 1988, t. 2, p. 1512.

${ }^{22}$ Aparecen formas como peidei, casaise, poi, guaidia, en Manuel CabreRA, Coplas del jibaro, Arecibo, 1820.

${ }^{23}$ En el anónimo diálogo titulado El orejano y el comerciante, que se publicó en El Telégrafo Constitucional de Santo Domingo del 26 de abril de 1821, hay formas léxicas como encerrai, pueicos, vendei, compraile, coimillos, daile, caigamento. Reproduce el texto E. Rodríguez Demorizi en su libro Lengua y folklore de Santo Domingo, Universidad Católica Madre y Maestra, Santiago de los Caballeros, 1975, pp. 28-29.

24 "Algunos [de los negros criollos] que se titulan curros usan la $i$ por la $r$ y la $l$ : "poique el niño puee considerai que es mejoi dinero que papei»", en Esteban Pichardo TaPia, "Prólogo", Diccionario provincial casi razonado de vozes y frases cubanas, Matanzas, 1836. Véase ahora la reproducción de la $4^{\text {a }}$ edición de esta obra (La Habana, 1875) publicada en La Habana, 1976.

25 "Desfiguración a que está expuesto el idioma castellano al contacto y mezcla de razas", Revista de Cuba, 14 (1883), 97-104.

${ }^{26}$ En su obra El jibaro aparecen formas como pueyta, tayde, vueyve, papey, comey, laygo, tueyto, mejay, etc. Véase ahora la edición conmemorativa publicada en San Juan, 1949. 
Eusebio Núñez en $1858^{27}$ y Salvador Brau en $1894^{28}$ y, para Santo Domingo, entre otros, el de Juan Antonio Alix ${ }^{29}$. Bien es verdad que algunas indicaciones sueltas ${ }^{30}$ parecen hacer pensar en posibles diferencias entre las tres áreas por lo que respecta a la vitalidad relativa que, en cada una de ellas, debió de tener el rasgo aquí estudiado.

Por el contrario, es ampliamente discordante la fisonomía que ofrece, en cada una de las islas antillanas hispanoparlantes, la desconsonantización de líquidas postnucleares por lo que atañe tanto a los grupos sociales que emplearon, en su habla, esta realización fonética como a la fijación del segmento temporal en que la misma fue mayoritariamente eliminada del uso comunitario.

En cuanto a la primera de las cuestiones mencionadas, la desconsonantización de /L/ y /R/ implosivas silábicas es unánimemente atribuida en Cuba, durante el siglo xIx, a la modalidad lingüística utilizada por los negros curros, grupo sociológico marginal constituido por negros criollos libres que, en los barrios costeros de la bahía de La Habana y también, al parecer, en Matanzas y en Cárdenas, se dedicaban, mayoritariamente, a la delincuencia y se diferenciaban del resto de la población de color de la isla por usos, costumbres y atavíos característicos ${ }^{31}$. Así se de-

${ }^{27}$ En las coplas de este autor al nacimiento del que sería Alfonso XII, en 1858, hay formas como oydenanza, afoytunao, caysones, ey. Véase MARía CADILLA, Costumbres y tradicionalismos de mi tierra, San Juan, 1938, pp. 105-106.

${ }^{28}$ En su obra Puerto Rico y su historia, Valencia, 1894, p. 135.

${ }^{29}$ Vivió entre 1833 y 1918. Véanse Décimas de Juan Antonio Alix, Santo Domingo, 1927.

${ }^{30}$ Por ejemplo, en la nota del director de la publicación habanera El Artista que, en su número de 31 de diciembre de 1848 (p. 318), precede a la publicación de las décimas tituladas "El negro José del Rosario" de José Victoriano Betancourt (en las que aparecen abundantes casos de desconsonantización de líquidas implosivas), se afirma que "en la actualidad sólo quedan recuerdos del curro del Manglar [ya que] la civilización progresiva del país [lo] ha borrado ya casi por entero", lo que parece indicar que el habla característica de este grupo social (y también, lógicamente, el rasgo fonético que aquí nos interesa) debía de hallarse en estado muy decadente, al menos en La Habana, ya en la mitad del siglo XIX.

31 Véase sobre este grupo social marginal, integrante del hampa de La Habana, Matanzas y Cárdenas principalmente, F. OrTIz, "Los negros curros. Sus caracteres: el lenguaje", Archivos del Folklore Cubano, 2 (1926), 209 220; 2 (1927), 285-325; 3 (1928), 25-50; 3 (1928), 160-175; 3 (1928), 250-256, y 3 (1928), 51-53. También Jeanine Potelet, "Dissonances de la societé cubaine des années 1830: Nègre cimarrón et nègre curro dans le roman de Cirilo Villaverde Cecilia Valdés", Crisol, Nanterre, 5 (1986), 51-67. 
duce de las menciones que, al tema, dedican desde Pichardo ${ }^{32}$ a Bachiller y Morales ${ }^{33}$ incluyendo, entre ellas, las numerosas que recopila F. Ortiz en sus monografías referentes al negro curro y sus peculiaridades $^{34}$. Por el contrario, en Puerto Rico el fenómeno lingüístico en cuestión fue considerado como propio de la población jíbara de los campos de la isla, en especial de la asentada en las áreas montañosas del centro y occidente de la misma ${ }^{35}$. Y, finalmente, en Santo Domingo, se ha valorado comunitariamente dicho rasgo como uso popular general de la comarca cibaeña, es decir de las áreas norteñas del país, mal y escasamente comunicadas, por razones simultáneamente geográficas y sociológicas ${ }^{36}$, con la ciudad capital y su zona de influencia.

Por lo que toca a la desaparición del fenómeno que consideramos, parece claro que la localización cronológica de este hecho (sin duda a través de un proceso lento y progresivo) debe fijarse, tanto para Cuba como para Puerto Rico, en las últimas décadas del siglo xix y primeras del actual como creen, entre otros, $\mathrm{H}$. López Morales ${ }^{37}$ y 'T. Navarro 'Tomás ${ }^{38}$ quien, en 1927-1928, sólo localizó ya restos escasísimos de semiconsonantización de líquidas postnucleares en áreas montañosas, muy aisladas y marginales, de Puerto Rico ${ }^{39}$. En Cuba la vigencia, muy minoritaria, del fenómeno ha debido de ser más amplia y prolongada temporalmente que en Puerto Rico como parecen indicarlo algunos casos subsistentes, aún hoy, en zonas rurales del territorio insular, en

32 Pichardo Tapia, loc, cit.

33 A. Bachiller y Morales, art. cit.

34 El trabajo de F. ORTIz citado en la nota 31 ha sido reproducido, juntamente con otros materiales (publicados e inéditos) referentes al tema, en el volumen del autor Los negros curros, Editorial de Ciencias Sociales, La Habana, 1986. En adelante citaré por este texto.

35 Cf. T. Navar ro Tomás, El español en Puerto Rico, Universidad de Puerto Rico, Río Piedras, 1974 (esp. pp. 84-86) y M. Álvarez Nazario, La herencia lingüistica de Canarias en Puerto Rico, Instituto de Cultura Puertorriqueña, San Juan, 1972 (pp. 70-71, esp. n. 27).

${ }^{36} \mathrm{Cf}$. el estudio clásico de P. Henríquez UReña, El español en Santo Domingo, Instituto de Filología, Buenos Aires, 1940.

37 " Las formas [pweita, taide, poike] no tienen existencia regular en Cuba, probablemente desde hace más de setenta años", en Humberto LóPEZ Mor ales, "Neutralizaciones fonológicas en el consonantismo final del español de Cuba", trabajo reproducido en el volumen del autor Estudio sobre el español de Cuba, Anaya, Madrid, 1971, p. 131.

38 T. Navarro Tomás, op. cit.

39 Concretamente en Lares y Adjuntas. 
especial en la antigua provincia de Oriente ${ }^{40}$. En contraposición con estos hechos, referidos a Cuba y Puerto Rico, la desconsonantización de /L/ y /R/ implosivas silábicas ha mantenido hasta el momento actual una elevadísima vitalidad sociolingüística en la mayor parte del territorio dominicano, lo que es explicable, simultáneamente, por razones de índole sociohistórica, que he intentado discriminar en una monografía anterior ${ }^{41}$, y por un complejo de actitudes comunitarias, de carácter sociolingüístico y psicológico, que ha analizado, muy penetrantemente, I. Pérez Guerra ${ }^{42}$.

A partir de los hechos hasta aquí reseñados muy abreviadamente (o, de modo más exacto, a partir de sólo algunos de ellos en la mayor parte de los casos) han sido propuestos varios modelos de análisis genético de los mismos. Los examinaremos, críticamente, a continuación, adoptando como criterio evaluador su adaptación o discordancia respecto del contexto lingüístico hispanoantillano general en primer lugar y, también, respecto a las matrices causales, generalmente peninsulares, propuestas. Todo ello sin perder de vista la inserción de los datos analizados dentro del área total hispanoamericana.

En 1926-1928 F. Ortiz ${ }^{43}$ insinuó, con toda clase de reservas, la posibilidad de que "la tendencia de los antillanos a cambiar en $i$ el sonido de $r$ y $l$ finales haya surgido de nuestro antiguo pueblo montuno en contacto con los indocubanos" ${ }^{44}$, alegando como argumento en favor de esta hipótesis los abundantes "nombres terminados en ey como Hatuey, siboney, baracutey", derivados, quizá, de formas preexistentes con $l, x$ o $j$ finales ${ }^{45}$.

La existencia de una matriz andaluza para la desconsonantización o vocalización de líquidas postnucleares fue ya sugerida, en 1883, por A. Bachiller y Morales ${ }^{46}$ (aunque no de modo ex-

${ }^{40}$ Así lo afirma, en monografía muy reciente, Luis R. CHOY LóPEz. Véase su trabajo "El consonantismo actual de Cuba", $L / L, 16$ (1985), 219-248 (p. 223). C. IsBĂSESCU, "Algunas peculiaridades fonéticas del español hablado en Cuba", RRL, 10 (1965), 571-594 (esp. 589), sólo encuentra un caso aislado de [aséi ].

41 "Consecuencias lingüísticas de un periodo histórico dominicano (la dominación haitiana, 1822-1844)", en Actas del III Congreso Internacional sobre el Español de América (en prensa).

42 I. Pérez Guerra, art. cit.

${ }^{43} \mathrm{~F}$. Ortiz, art. cit.

${ }^{44}$ Ibid., p. 75.

${ }^{45}$ Ibid., pp. 74-75.

${ }^{46}$ A. Bachiller y Morales, art. cit. 
elusivo). Aceptaron con posterioridad esta tesis A. Montori ${ }^{47}$ y F. Ortiz ${ }^{48}$, y, en un nivel de análisis más especializado y científico, M. L. Wagner ${ }^{49}$, P. Henríquez Ureña ${ }^{50}$ y el mismo A. Alonso $^{51}$, seguidos, en épocas más recientes, por especialistas como J. García González ${ }^{52}$ y, con matizaciones, H. López Morales $^{53}$.

La hipótesis de la procedencia canaria del fenómeno que nos ocupa fue ya considerada (aunque sin prescindir de resaltar la raíz andaluza de esta modalidad lingüística insular) por A. Montori ${ }^{54}$ y, más recientemente, aplicada al área puertorriqueña por M. Álvarez Nazario ${ }^{55}$ y a la dominicana por P. Golibart ${ }^{56}$.

Finalmente, en trabajos realizados en los últimos años, han propuesto la derivación del proceso de desconsonantización de /L/ y /R/ postnucleares de modeles lingüísticos de localización originaria negro-africana S. Valdés Bernal ${ }^{57}$ e I. Pérez Guerra ${ }^{58}$.

Podemos descartar, en principio, de entre las hipótesis causales hasta aquí mencionadas, como radicalmente insostenible la insinuada con timidez (e inmediatamente retirada por el propio autor) por F. Ortiz, de base sustratística taína. Tanto la inverosimilitud de la evolución $-e l>e i$, supuesta, para esta lengua, por el sabio cubano como el carácter puramente formal de la coincidencia entre este (supuesto) fenómeno con la actual desconsonan-

47 Modificaciones populares del idioma castellano en Cuba, Imprenta de Cuba Pedagógica, La Habana, 1916 (esp. p. 111).

48 F. Ortiz, op. cit., pp. 79-82, n. 34.

49 "El supuesto andalucismo de América y la teoría climatológica", RFE, 14 (1927), 20-30 (p. 24).

50 “'Observaciones sobre el español de América', RFE, 8 (1921), 357-390 (p. 373).

51 “-R y -L en España y América”, reproducido en Estudios lingüiśticos. Temas hispanoamericanos, Credos, Madrid, 1967, pp. 213-267 (p. 263).

52 "Acerca de la pronunciación de $\mathrm{R}$ y $\mathrm{L}$ implosivas en el español de $\mathrm{Cu}$ ba: variantes e influencias", Islas, 65 (1980), 115-127.

53 "Elementos africanos en el español de Cuba", reproducido en el volumen del autor Estudio sobre el español de Cuba, Madrid, 1971, pp. 62-71 (esp. p. 68).

${ }^{54}$ A. Montori, op. cit.

${ }^{55} \mathrm{M}$. Álvarez Nazario, op. cit.

56 P. Golibart, art. cit.

57 "Las lenguas africanas y el español coloquial de Cuba", Santiago, 31 (1978), 81-107 (esp. p. 92).

58 "Africanismos lingüísticos en la República Dominicana. Notas metodológicas', en Estudios sobre español de América y lingüística afroamericana, Bogotá, 1989, pp. 354-368 (p. 368). 
tización de líquidas postnucleares en el Caribe hispánico bastan para negar todo crédito a la suposición mencionada. A lo que podríamos añadir, como argumentos en el mismo sentido, la brevedad temporal del contacto entre el español y las hablas taínas (menos de medio siglo), insuficiente para fundamentar interferencias estructurales de éstas sobre aquél, y la inexistencia, absoluta, de fenómenos de índole similar al postulado, en este punto, por F. Ortiz en el español caribeño ${ }^{59}$.

Muy diferente parece ser, a primera vista, el valor que debe ser atribuido a la hipótesis andalucista sobre el origen del rasgo fonético que examinamos en estas páginas.

Aunque, a pesar de los esfuerzos realizados por F. Ortiz ${ }^{60} \mathrm{pa}-$ ra fundamentarla, no queda clara la derivación de la modalidad lingüística empleada en Cuba por los negros curros del siglo pasado (y, por lo tanto, de su desconsonantización de /R/ y /L/) respecto al habla "andaluzada" de los guajiros del interior de la isla, esta circunstancia carecería de relevancia si se demostrara la existencia, en los dialectos meridionales de la Península, de dicho concreto fenómeno fonológico. De ser éste el caso, la excepcional densidad del poblamiento andaluz en las Antillas, demostrada contundentemente por P. Boyd-Bowman ${ }^{61}$, podría constituir la fundamentación explicativa de la difusión del mismo en el área caribeña hispanoparlante y no en otras áreas americanas, de demografía menos marcada por los contingentes colonizadores andaluces.

No ocurre, sin embargo, así. Ni en la dialectología andaluza actual ni en los textos literarios de siglos pasados que se han propuesto reflejar los usos lingüísticos locales (Fray Pedro Beltrán, Gaspar Fernández y Ávila) ni en los documentos de archivo escritos o copiados en Andalucía ${ }^{62}$ se han podido detectar ejemplos de desconsonantización de líquidas postnucleares.

59 Véase lo que digo en mi trabajo "La velarización de $/ \bar{R} /$ en el español de Puerto Rico", reproducido ahora en G. DE GRANDA, Estudios lingüisticos hispánicos, afrohispánicos y criollos, Gredos, Madrid, 1978, pp. 11-79, sobre la tesis, propugnada por T. Navarro Tomás, de la génesis taína de la velarización de la vibrante múltiple castellana en Puerto Rico (pp. 37-41). Los argumentos allí presentados por mí en contra de esta hipótesis causal pueden ser pertinentes también respecto al tema tratado en estas páginas.

${ }^{60}$ F. Ortiz, op. cit., n. 34, passim.

${ }^{61}$ Cf. su trabajo de síntesis, "Patterns of Spanish emigration to the Indies till 1600", HAHR, 56 (1976), 580-604. Hacia 1600 los andaluces o sus descendientes constituían el $49.8 \%$ de los pobladores de Santo Domingo y el 44.4\% de los de Cuba, según los datos presentados por P. Boyd-Bowman.

${ }^{62}$ Véase sobre este punto lo que indica José Mondéjar Cumpián en su 
Parece probable que los investigadores que han relacionado la existencia de este fenómeno en áreas del Caribe hispánico con supuestos condicionamientos causales andaluces, de A. Montori a A. Alonso, hayan basado su hipótesis en el testimonio de $\mathrm{H}$. Schuchardt quien, en su monografía Die Cantes Flamencos ${ }^{63}$, recoge, efectivamente, formas léxicas con /L/ y /R/ postnucleares semivocalizadas. Es muy posible, sin embargo, que estos textos hayan sido facilitados a Schuchardt por sus amigos andaluces F. Rodríguez Marín y A. Machado y Álvarez (en cuyas obras aparecen casos semejantes) y, dada la ignorancia de los mismos de las normativas y convenciones técnicas referentes a la captación y transcripción fonética ${ }^{64}$, sus aportaciones han podido presentar graves inexactitudes referentes, en concreto, al rasgo que aquí consideramos.

Como dice $J$. Mondéjar ${ }^{65}$ al tratar el tema de la postulada desconsonantización de líquidas implosivas silábicas en Andalucía, los testimonios de Rodríguez Marín, Machado y Álvarez e, incluso, Schuchardt indican sólo o "una errónea interpretación de la infrecuente aspiración de /R/ ante oclusiva por parte de los eruditos o [...] una generalización injustificada por parte de los mismos de unos casos en que algún medialengua o bobo los

monografía "En los orígenes de la dialectología andaluza. II. Etapa precientífica", en Estudios román eos dedicados al Profesor Andrés Soria Ortega, Granada, 1985, t. 1, pp. 193-220. Es cierto que en el excelente trabajo de JuAn ANTONio FraGo Gracia, "La fonética del español meridional y sus fuentes históricas", en Miscellània Sanchis Guarner, Valencia, 1984, t. 2, pp. 131-137, aparece un aislado ejemplo de vocalización de /-R/ en su documento trasladado en Sevilla en 1474 (Puychena por Purchena), pero, en mi opinión, este hápax no constituye prueba convincente de la existencia en el habla andaluza del fenómeno que aquí consideramos. Nuevas investigaciones deberán aclarar el problema, respecto del cual creo lícito mantener, por ahora, una actitud negativa.

${ }^{63}$ En $Z R P h, 5$ (1881), p. 317. Véase sobre este trabajo y su valoración dentro de los estudios de dialectología andaluza, Juan Martínez Ruiz, "Hugo Schuchardt y las hablas andaluzas', RDTP, 35 (1979-80), 3-32.

${ }^{64}$ Hay casos de desconsonantización de líquidas postnucleares en A. Machado y Álvarez, Colección de cantes flamencos, Sevilla, 1881 ( $2^{\mathrm{a}} \mathrm{ed}$., Madrid, 1974). En este mismo volumen el autor, buen amigo e informador de Schuchardt, confiesa que carece de conocimientos fonéticos (p. 21 de la $2^{\mathrm{a}}$ edición) y que transcribe en sus publicaciones "lo que hemos oído o, al menos, hemos creído oír" del habla popular ( $2^{a}$ edición, p. 23). En otra obra, De soledades. (Escritos flamencos), publicada en 1879 ( $2^{\text {a }}$ edición, Córdoba, 1982) también dice carecer de un "sistema ortográfico" que le permita representar las modificaciones fonéticas de las hablas andaluzas $\left(2^{\mathrm{a}}\right.$ edición, p. 12, n. 7).

${ }^{65} \mathrm{~J}$. MONDÉJAR, art. cit. 
dijese" ${ }^{66}$. En ambos casos cae por su base la construcción teórica de componente causal andaluz, que ha intentado fundamentar, sobre este modelo explicativo, la producción del rasgo fonético que aquí estudiamos en el área del Caribe hispánico.

Más sólidos son los datos básicos de los que parte la hipótesis de la génesis canaria del fenómeno en cuestión, propugnada para Puerto Rico por Álvarez Nazario, para Santo Domingo por Golibart y (parcialmente) para Cuba por A. Montori.

Es indiscutible la importancia que, en la demografía de estos territorios, revistió la inmigración "isleña" de los siglos XVII y $\mathrm{XVIII}^{67} \mathrm{y}$ también lo es el que existen aún, aunque muy decadentes y minoritarios, casos de desconsonantización de /R/ y /L/ postnucleares tanto en localidades de Tenerife ${ }^{68}$ como en el habla del enclave hispanohablante de Saint Bernard Parish, Louisiana ${ }^{69}$, vestigio aún vivo de la modalidad lingüística canaria del siglo XviII. Todo lo cual deja fuera de duda el hecho de que el fenómeno mencionado se dio (y posiblemente con mucho mayor vigor que el que hoy posee en el archipiélago) en algunas variedades, al menos, del dialecto canario de siglos atrás y pudo haber sido transmitido a las Antillas españolas por medio de la fuerte corriente migratoria que, procedente de las Islas Afortunadas, se dirigió al área caribeña durante, por lo menos, dos centurias.

Pero al mismo tiempo, determinadas circunstancias, de significación contrapuesta a las que acabamos de mencionar, relativizan apreciablemente la aplicabilidad de esta tesis explicativa, so-

66 Ibid., p. 214.

67 Para el planteamiento general del tema véase J. PÉrez VIDal, “Aportación de Canarias a la población de América”, Anuario de Estudios Atlánticos, 1 (1955), 91-197 y F. Morales PADrón, "Los canarios y la política migratoria a Indias", I Coloquio de historia canario-americana, Las Palmas, 1977, pp. 21 291. Sobre la emigración canaria a Puerto Rico da numerosos datos M. ÁLVAREZ NaZARIO, op. cit.; sobre la corriente migratoria del mismo origen dirigida a Santo Domingo véase G. De Granda e I. Pérez Guerra, art. cit.

68 Entre "viejos pescadores de Punta del Hidalgo y Puerto de la Cruz", según D. CataláN en su estudio "El español en Canarias", reproducido ahora en el volumen del autor El esp.ñol. Orígenes de su diversidad, Madrid, 1989, pp. 145-201 (p. 182). Y, según J. PÉrez VIDAL, art. cit., p. 179, "en el habla de gente de mar'”.

${ }^{69}$ Cf., sobre este tema, R. McGurdy, The Spanish dialect of Saint Bernard Parish, Louisiana, Alburquerque, 1950 y "Los isleños de Luisiana. Supervivencia de la lengua y folklore canarios", en Anuario de Estudios Atlánticos, 21 (1975), 471-591. Datos etnográficos y etnohistóricos de este grupo sociológico facilita JOSEPH GuiLlote, Masters of the Marsh. An introduction to the ethnography of the Isleños of Lower St. Bernard Parish, Louisiana, New Orleans, 1982. 
bre todo en lo que se refiere a las zonas cubana y dominicana.

Por lo que toca a Cuba no sólo aparece como indemostrable la posibilidad de que la modalidad lingüística de los negros curros se haya constituido sobre un modelo isleño, a través de la etapa intermedia del habla del guajiro rural, sino que tal planteamiento carece de cualquier tipo de fundamentación sociohistórica medianamente consistente.

En cuanto a la zona dominicana, dos tipos de consideraciones, de índole diatópica las primeras y de carácter sociolingüístico las otras, levantan fuertes dudas sobre la adecuación a parte, al menos, de este territorio de la tesis causal, de base canaria, propuesta por P. Golibart en relación con el proceso local de desconsonantización de líquidas postnucleares.

En primer lugar, y desde un enfoque de áreas, no existe en absoluto este fenómeno hoy (y no parece tampoco haber existido anteriormente) en ninguna de las localidades del suroeste del país que recibieron poblamiento canario, a veces exclusivo, en los siglos XVII y XvIII ${ }^{70}$ como San Carlos, Azua y, sobre todo, Baníi1 . Tampoco se da, o se da muy débilmente, en zonas de población originaria isleña como Montecristi, en la costa norte, y Sabana de la Mar en la costa este de la isla ${ }^{72}$. Y, por el contrario, el primer testimonio del mismo, en 1821, es referido a campesinos de San Francisco de Macorís ${ }^{73}$, localidad fundada y poblada desde La

${ }^{70}$ Cf. para lo referente al establecimiento de canarios en el occidente y suroccidente del área dominicana, Frank Moya Pons, Historia colonial de Santo Domingo, Universidad Católica Madre y Maestra, Santiago de los Caballeros, 1974 (esp. pp. 283-290); María Rosario Sevilla Soler, Santo Domingo tierra de frontera (1750-1800), Sevilla, 1980, y Antonio Gutiér rez Escudero, Población y economía en Santo Domingo (1700-1746), Sevilla, 1985 (esp. pp. 64-75).

${ }^{71}$ Sobre la historia de este núcleo poblacional, de origen isleño, que ha mantenido en algunos de sus campos una sorprendente cohesión racial, véanse F. Henríouez y Carvajal, Baní, parcela histórica de su vida en la villa y en el valle, Ciudad Trujillo, 1939; Alcides García Lluberes, Baní, documentos relativos a la celebración del 177 aniversario de la fundación, Ciudad Trujillo, 1944; S. OBjío, Bani, cosas antiguas, Ciudad Trujillo, 1958; Joaquín S. InCháustegui, Baní, reseña histórica, Baní, 1972. Sobre las tensiones raciales entre los campos blancos (Paya Arriba, Bocacanasta, El Llano, Sombrero, Matanzas, Sabana Buey y El Cañafístol) y la población local de color, cf. WALter Cordero, "Actitudes y tensiones raciales en la sociedad banileja", Liberación, Santo Domingo, 2 (1971), p. 33. Durante una breve encuesta que realicé en 1985 en Bocacanasta pude comprobar que los moradores de esta área aún conservan conciencia de su origen isleño (canario).

72 Véase L. Coupal, art. cit.

${ }^{73}$ Cf. supra, n. 23 
Vega y en la que no se establecieron nunca contingentes humanos de procedencia canaria.

Aún parece menos aceptable la postura de P. Golibart ${ }^{74}$ cuando postula, para justificar la extensión del fenómeno fonético en cuestión a toda el área septentrional dominicana, la imitación por la población local de blancos de la tierra (mulatos y negros) de este rasgo, empleado originalmente sólo por los canarios, imitación debida, según su tesis, al superior prestigio del uso lingüístico de los blancos isleños. Ni la fragmentación sociológica del territorio cibaeño, debida a factores geográficos de difícil superación ${ }^{75}$, permite explicar de este modo la difusión a comarcas centrales como las de Moca, Cotui o San Francisco de Macorís ${ }^{76}$ de modelos lingüísticos supuestamente procedentes de zonas laterales o costeras como las de Montecristi, Puerto Plata, Samaná, Sabana de la Mar, San Rafael, Hincha o Bánica, de población canaria, ni parece tampoco creíble que los orgullosos blancos de la tierra hayan podido tomar como modelos de lengua a los grupos de labradores isleños, pobres e ignorantes por lo común, a los que, entre otros, el criollo dominicano Antonio Sánchez Valverde describe, en la segunda mitad del siglo XVIII, como "familias miserables", viviendo en " "pobres rancherías"', plagadas de enfermedades y sometidas a una continua mortandad ${ }^{77}$. El modelo lingüístico prestigioso de los ha-

${ }^{74}$ Cf. P. Golibart, art. cit.

${ }^{75}$ Sobre este punto véanse las precisiones que facilita Frank MOYa PONS en sus trabajos "Las luchas constitucionales en el siglo XIX" y "Modernización, industrialización y cambios en el siglo $\mathrm{xx}$ ", reproducidos ambos en el volumen del autor El pasado dominicano, Santo Domingo, 1986, pp. 171-184 y 207-251 respectivamente. También las consideraciones referentes a la regionalización histórica de la sociedad dominicana que hace José Oviedo en su trabajo "Cultura y nación: la búsqueda de la identidad", Boletín del Museo del Hombre Dominicano, 20 (1987), 109-118 (esp. pp. 110-111).

${ }^{76}$ Son precisamente estas zonas, enclavadas en el área territorial interior de la comarca cibaeña (y que no recibieron jamás poblamiento canario), las que en la actualidad presentan más altos índices de desconsonantización de líquidas implosivas. Según C. González TAPIA, art. cit., Moca tiene un $83.9 \%$ de este fenómeno para /-L/y un $68 \%$ para $/-\mathrm{R} /$, Cotui $66.6 \%$ y $50.9 \%$ respectivamente y San Francisco de Macorís $82.3 \%$ y $65.2 \%$.

${ }^{77}$ Sobre el orgullo del "blanco de la tierra" dominicano (mulato o negro) véanse los testimonios que prestan, involuntariamente, sobre el mismo los franceses Gilber t GuILlER min, Diario histórico (Guerra dominicano-francesa de 1808), Santo Domingo, 1976 y Lemonnier Delafosse, Segunda campaña de Santo Domingo, Santiago de los Caballeros, 1946. Los textos de Antonio Sánchez Valverde proceden de su obra Idea del valor de la Isla Española, publicada en Madrid en 1785. Utilizo aquí la edición de este libro que está contenida en el vo- 
bitantes rurales del territorio septentrional dominicano debió de estar constituido, más bien, por el habla de las localidades urbanas de la zona como Santiago de los Caballeros o La Vega, de cuya riqueza económica y carácter social aristocrático y refinado (durante el siglo XVIII) tenemos abundantes referencias documentales y literarias ${ }^{78}$.

Bastan, creo, los datos hasta aquí apuntados para limitar la aplicabilidad del modelo explicativo, de base canaria, desarrollado y propuesto por M. Álvarez Nazario y P. Golibart, a algunos determinados territorios caribeños (Puerto Rico, áreas de Cuba y Santo Domingo) y rechazar, al mismo tiempo y por idénticas razones, su validez como factor causal exclusivo del fenómeno global antillano de la desconsonantización de /L/ y /R/ postnucleares.

Por último, en cuanto se refiere a la hipótesis, recientemente expuesta ${ }^{79}$, de que el rasgo fonético de que aquí nos ocupamos puede ser conectado genéticamente con condicionamientos atribuibles, primariamente, a códigos de comunicación africanos manejados en las Antillas por determinados segmentos de su población esclava durante los siglos XVI-XIX y, secundariamente, a hablantes de español (monolingües o bilingües) que habrán adquirido estas características articulatorias a través de su contacto, intenso y frecuente, con aquéllos, debo reconocer la evidencia de los datos aducidos por la última propugnadora de esta posición teórica ${ }^{80}$ respecto de la fuerte incidencia que ha tenido en Santo Domingo, en muy amplios ámbitos de su vida colectiva (y también en el lingüístico), la aportación poblacional de origen africano. Al mismo tiempo que valoro, en toda su importancia, la sugestiva relación que esta investigadora establece entre la desconsonantización antillana de líquidas postnucleares y el fenómeno homólogo que se verifica, según testimonian los resultados de mis propios trabajos de campo en las zonas del litoral pacífico colombiano ${ }^{81}$, entre gru-

lumen de A. Sánchez Valverde, Ensayos, Santo Domingo, 1988. Las citas del texto se encuentran en las páginas 203, 226 y 299 de esta edición.

${ }_{78}$ Véanse los numerosos datos que recoge sobre este tema P. Henríquez Ureña en su excelente y documentado trabajo La cultura y las letras coloniales en Santo Domingo (sobre todo en los capítulos dedicados al siglo xviII, la emigración de 1795-1801 y el periodo final de la colonia española). Se encuentra reproducido en P. Henríquez Ureña, Obra Crítica, F.C.E. México, 1960, pp. 331-444.

${ }^{79}$ Cf. S. Valdés Bernal, art. cit. e I. Pérez Guerra, "Africanismos lingüísticos...".

80 1. Pérez Guerra, ibid.

${ }^{81}$ Véase G. DE GRANDA, Estudios sobre un área dialectal hispanoamericana de 
pos de mineros negros asentados en remotas regiones del curso alto del río Iscuandé (Departamento de Nariño). Podría, incluso, precisar, reforzando así el sentido de esta última puntualización, que existe también desconsonantización de /L/ y /R/ implosivas silábicas en zonas de los departamentos colombianos del Cauca, Chocó y Bolívar ${ }^{82}$, en el portugués de los estados brasileños de Alagoas, Pernambuco ${ }^{83}$, y Ceará ${ }^{84}$ y en el criollo portugués de Santiago de Cabo Verde ${ }^{85}$, todas ellas áreas de numerosa (o total) población negra de origen africano.

Dos razones me hacen, sin embargo, afirmar que los factores causales derivados de matrices lingüísticas africanas no han podido determinar, en proporción relevante, la producción del rasgo fonético que en estas páginas consideramos.

Es la primera la inexistencia o marcada escasez de población de procedencia africana en zonas que, como el área montañosa central de Puerto Rico o determinadas regiones del oeste y centro de Cuba, parecen haber incorporado en épocas pasadas a sus modalidades locales de lengua el fenómeno fonético de la desconsonantización de líquidas postnucleares ${ }^{86}$. $Y$, en segundo pero todavía más importante lugar, el dato, difícilmente eliminable y aún menos discutible, de que, en su práctica totalidad, las lenguas negroafricanas del oeste y noroeste, es decir las pertenecientes al am-

población negra. Las tierras bajas occidentales de Colombia, Instituto Caro y Cuervo, Bogotá, 1977. Los datos referentes a la existencia de desconsonantización sistemática de /R/ y /L/ implosivas entre mineros negros del curso alto del río Iscuandé se encuentran en el volumen citado, pp. 78-80.

82 Cf. Luis Flórez, La pronunciación del español en Bogotá, Instituto Caro y Cuervo, Bogotá, 1951, pp. 202-203 y 227-228.

83 Cf. M. Marroquim, A língua do Nordeste (Alagoas e Pernambuco), Companhia Editorial Nacional, São Paulo, 1945, pp. 86-87.

84 F. Seraine, "Contribuição ao estudo da pronúncia cearense', Anais do I Congresso da Lingua Nacional Cantada, Sáo Paulo, 1938, pp. 462 y 464.

${ }^{85}$ B. Lopes da Silva, $O$ dialecto crioulo de Cabo Verde, Lisboa, 1957, pp. 101 y 104

86 En el caso de Puerto Rico, la neta diferenciación existente en siglos pasados (y aún hoy) entre el campesino jíbaro, blanco, del interior montañoso del país y el peón cañero, negro o mulato por lo general, de las zonas bajas del litoral ha sido excelentemente expresada en M. Meléñez MuÑoz, Estado social del campesino puertorriqueño, San Juan, 1916 y "El jíbaro en el siglo xıx', en sus Obras Completas, Instituto de Cultura Puertorriqueña, San Juan, 1963, t. 3, pp. 459-611. Para la situación, en este aspecto, de Cuba, cf. F. Ortiz, Contrapunteo cubano del tabaco y el azúcar, J. Montero, Santa Clara, 1963 (hay numerosas ediciones) y Jesús GuANCHe, Procesos etnoculturales de Cuba, La Habana, 1983. 
plio phylum Niger-Kordofan ${ }^{87}$, no poseen (o, al menos, son en ellas extremadamente escasas) secuencias fónicas constituidas por vocal media o baja seguida de semivocal ${ }^{88}$. Lo que, en principio, parece descartar la posibilidad de que las mismas hayan podido facilitar al español caribeño, por lo menos de modo directo, la pauta articulatoria que subyace en la realización fonética que en este trabajo nos ocupa.

Como resultado final del examen crítico que hasta aquí hemos realizado de las diferentes hipótesis propuestas sobre la génesis causal del fenómeno antillano de la desconsonantización de líquidas postnucleares hemos llegado a la conclusión de que algunas de ellas son insostenibles de modo total, mientras que las otras sólo son aplicables a determinadas zonas territoriales del Caribe hispánico pero no al resto de ellas. En todos los casos examinados la motivación que nos ha llevado a adoptar las posiciones, parcial o totalmente, negativas en cuestión deriva, de modo aislado o conjunto, o bien de la carencia, en todas y cada una de las tesis causales propuestas, de fundamentación correcta y adecuada desde el punto de vista lingüístico o bien de la utilización de categorías sociohistóricas de análisis que son de aplicación imposible a la totalidad diatópica del área antillana afectada por la problemática analizada.

Así pues, la propuesta, por nuestra parte, de una hipótesis causal alternativa a las hasta aquí consideradas debe venir, de manera obligada, de puntos de partida teóricos que no sean susceptibles de caer en los mismos errores metodológicos atribuidos a aquéllas. Refiriéndonos, en primer lugar, al último de los criterios mencionados, es decir, a la aplicabilidad al conjunto de las zonas territoriales y grupos sociales implicados en la realización del fenómeno fonético que nos ocupa de una categoría sociohistórica común que pueda dar razón correctamente de su compartida peculiaridad lingüística en cuanto a este rasgo fonético concreto, pienso que, descartados en este sentido tanto la presencia de poblamiento canario como el influjo de códigos de comunicación africanos, sólo es ad-

${ }^{87}$ Respecto de la extensión de esta familia lingüística y de las lenguas incluidas en ella es indispensable J. H. GreEnBerG, The languages of Africa, Bloomington, 1963.

${ }^{88}$ Véanse las páginas que dedica al repertorio fonético de las lenguas del grupo Niger-Kongo W. E. WeLmERs en su excelente African language structures, University of California, Los Angeles, 1973. También D. Westermann e I. WARD, Practical phonetics for students of African languages, Oxford, 1933, y P. LADEFoged, A phonetic study of West African languages, Cambridge, 1968. 
misible como tal la noción sociológica de marginalidad periférica ${ }^{89}$. En efecto, la totalidad de los grupos sociológicos antillanos entre los que se ha desarrollado el proceso de desconsonantización de líquidas postnucleares comparten esta nota caracterizadora, ya por razones geográficas (jíbaros de la montaña puertorriqueña, habitantes del Cibao dominicano, guajiros cubanos), ya por razones sociológicas (negros curros del hampa habanera), lo que, al mismo tiempo, implica la inclusión de dichos grupos humanos en la periferia lingüística ${ }^{90}$ de las sociedades mayores en las que se integran y, por lo tanto, su máximo alejamiento respecto de los centros de influencia de las mismas, desde los que se difunden, como es evidente, las normas prestigiosas comunitarias.

Ahora bien, es sabido que precisamente es en las áreas sociológicas o geográficas marginales o periféricas en las que, al mismo tiempo que se dan fenómenos de máxima retención de elementos léxicos o gramaticales arcaicos, se verifica, con intensidad también máxima ${ }^{91}$, el desarrollo de tendencias radicales de simplificación estructural ${ }^{92}$, en especial en los segmentos fonéticos o rasgos gramaticales caracterizados por su debilidad articulatoria ${ }^{93}$ o por su opacidad semántica o también por su alomor-

${ }^{89}$ Cf., sobre este concepto teórico, S. M. SAPON, "A methodology for the study of socio-economic differentials in linguistic phenomena", Studies in Linguistics, 2 (1953), 57-68.

${ }^{90}$ Respecto de la noción de periferia lingüística véanse B. MALMBERG, " L'extension du castillan et le problème des substrats", Actes du Colloque Inter. national de Civilisations, Littératures et Langues Romanes, Bucarest, 1959, pp. 249 259; "Linguistique ibérique et ibéro-romane. Problèmes et méthodes", Studia Linguistica, 15 (1961), 57-113, y “Diferenciación social y evolución lingüística”, I Simposio Internacional de Lengua Española, Las Palmas, 1981, pp. 15-30.

91 Un notable ejemplo de coexistencia de fuerte retención de rasgos arcaicos y de desarrollo de tendencias simplificadoras de carácter sorprendentemente violento en un área marginal del occidente de Colombia puede verse en mi trabajo "Neutralización de fonemas consonánticos en distensión silábica en San Juan de Micay", ahora reproducido en GERMán dE GRANDA, Estudios sobre un área dialectal hispanoamericana de población negra. Las tierras bajas occidentales de Colombia, Bogotá, 1977, pp. 128-148.

92 Cf. sobre este concepto metodológico B. MalmberG, "Minimal systems, potential distinctions and primitive structures", Proceedings of the $V^{\text {th }}$. International Congress of Linguists, Cambridge, 1962, pp. 78-83.

93 Cf., entre otros trabajos atingentes al tema, R. LAss, English phonology and phonological theory, Cambridge University Press, Cambridge, 1976; J. FoLEY, Foundations of phonological theory, New York, 1977. También J. W. Harris, Spanish phonology, MIT Press, Cambridge, MA, 1969 y J. B. Hooper, An introduction to natural generative phonology, Academic, New York, 1976. 
fia morfosintáctica ${ }^{94}$ respectivamente.

Creo que, al igual que se ha propuesto para otros fenómenos homólogos del área hispánica de América ${ }^{95}$, el rasgo antillano consistente en la desconsonantización de líquidas postnucleares puede ser considerado, en cuanto a su dimensión genética, como resultado de un drástico proceso, desarrollado en áreas o grupos marginales o periféricos (bien geográficos, bien sociológicos), de simplificación de realizaciones en elementos fonéticos caracterizados por su especial debilidad posicional silábica ${ }^{96}$.

De modo más concreto, y adoptando una noción teórica acuñada por R. Lass ${ }^{97}$ y ampliada y matizada por G. Chela Flores ${ }^{98}$, se podría conceptualizar dicho proceso como dirigido a la consecución radical de la consonante líquida mínima, sin contacto articulatorio, mediante un mecanismo basado en la retracción lingual.

Lo que, desde luego, es perfectamente compatible con el hecho, muy probable, de que en algunas áreas territoriales antillanas este proceso de regulación causal básicar ıente interna, aunque de desarrollo determinado por factores sociológicos ${ }^{99}$, pueda haber sido reforzado por la existencia, concomitante, en ellas de fenómenos fonéticos similares utilizados, en sus modalidades lin-

${ }^{94} \mathrm{Cf}$, , en relación con estas nociones teóricas, P. KIPARSKY, "Historical Linguistics", en W. O. Dingwall (ed.), A survey of linguistic science, Linguistic Program University of Md., College Park, 1971, pp. 476-562, y "Abstractness, opacity and global rules", en A. Koutsoudas (ed.), The application and ordering of grammatical rules, Mouton, Paris, 1976, pp. 160-186. Además, los apartados pertinentes de H. H. Hock, Principles of historical linguistics, Berlin, 1986.

$95^{2}$ Véanse, como ejemplos, J. M. Guitart, Markedness and a Cuban dialect of Spanish, Georgetown University Press, Washington, 1976; R. A. Núñez CEDEÑO, "Procesos finales en el español de Santo Domingo", NRFH, 29 (1980), 128-138, y mi propio trabajo "Neutralización de fonemas consonánticos en distensión silábica en San Juan de Micay".

96 Cf., entre otras, J. W. HARris, Syllable structure and stress in Spanish: a nonlinear analysis y J. B. HoOPER, op. cit., de esta última, también, "The syllable in phonological theory', Lan, 48 (1972), 325-407. Recoge y examina acertadamente gran cantidad de datos hispánicos pertinentes al tema JULIO FER. NÁNDEZ SEvilla, "Los fonemas implosivos en español”, BICC, 35 (1980) (cito por separata).

97 R. LASS, $o p$. cit.

98 "Las teorías fonológicas y los dialectos del Caribe hispánico", en R. E. Núñez Cedeño, I. Páez. Urdaneta y J. M. Guitart (eds.), Estudios sobre la fonología del español del Caribe, La Casa de Bello, Caracas, 1986, pp. 21-30.

99 Para la interacción teórica entre estos dos tipos de condicionamiento genético véase $\mathrm{J}$. VACHEK, "On the interplay of external and internal factors in the development of language', Lingua, 11 (1962), 433-448. 
güísticas propias, por núcleos poblacionales de origen canario y (con menos probabilidad) africano ${ }^{100}$.

Germán de Granda

Universidad de Valladolid

${ }^{100}$ Se trataría, pues, de un caso más de causación múltiple en la dialectología hispanoamericana. Cf., acerca de esta noción metodológica, el ya clásico trabajo de Y. MALKIEL, "Multiple versus simple causation in linguistic change", en To Honor Roman Jakobson, Mouton, The Hague, 1967, t. 2, pp. 1228-1246. 